\title{
The Solutions and Practical Results for Permafrost Engineering Problems of Qinghai -Tibet Railway*
}

\author{
Shun-Hua Xu and Zhi-Jian Wu \\ Lanzhou Institute of Seismology, CEA Lanzhou, Gansu 730000, China \\ E-mail:xshunh@163.com \\ Lu-Xin Zhang \\ The Northwest Research Institute, CREC Lanzhou, Gansu 730000, China \\ E-mail: zlx1947@163.com
}

\begin{abstract}
The Qinghai-Tibet Railway (QTR) is the highest-elevation one for passenger trains in the world and the first railway to connect central China with Tibet. It has kept operating very well for nearly 10 years so far. In this paper, the major solutions to geotechnical problems of permafrost for the construction and their effects are investigated, which are active methods of crushed roadbeds, heat pipe roadbed and dry bridges for construction. The major engineering problems, railway embankment cracks and deformation after operation and their solutions are given, which are active protections of more slice stones along embankment slopes, extra heat pipes along sunny embankment slope and reclaimed soil to keep from water. The observations from the long-term monitoring system have shown that the engineering protections of the Qinghai-Tibet Railway are completely successful no matter what design, construction, and operation.
\end{abstract}

Keywords: Qinghai-Tibet Railway; Permafrost; Engineering Problems; Monitoring system; Embankment deformation and cracks; Ground temperature

\section{Permafrost Engineering Problems in Construction of Qinghai - Tibet Railroad}

The Qinghai-Tibet Railway (QTR) was put into test operation On July 1, 2006. QTR is the highest-elevation railway for passenger train in the world and the first railway to connect central China with Tibet. Stretching about $1,142 \mathrm{~km}$, it

\footnotetext{
* This work is supported by the Gansu natural science research fund (No. 145RJZA165) and the open fund of State Key Laboratory of frozen soil engineering (No. SKLFSE201104).

This research is financially supported by the Gansu natural science research fund (No. 145RJZA165) and the open fund of State Key Laboratory of frozen soil engineering (No. SKLFSE201104). The Northwest Research Institute, China Railway Engineering Corporation and Prof. Ma Wei, Prof. Niu Fujun, Dr. Sun Zhizhong, Dr. Liu Kun, and Mr. Ma Linwei provided some data, advice and assistance for our research and paper preparing.
} 
runs from Golmud in Qinghai province to Lhasa, the capital city of the Tibet Autonomous Region, China.

How to keep the stability of embankment in permafrost regions is the most serious scientific and technical challenge for scientists and engineers, because of the influences of thermal variations due to the artificial disturbance during construction of QTR and the increase of environmental temperature in the future.

QTR crosses $546.41 \mathrm{~km}$ continuous permafrost regions. The permafrost is a very special soil, and it is quite sensitive to temperature. As a result of the influences of global climate warming and railway engineering on the permafrost degradation, stabilizing permafrost is the most pervasive challenge for both construction and maintenance of the railway. Protecting the permafrost is a key to preventing embankment and roadbed failure from frost heaving and thaw collapse, two main roadbed diseases from the degradation of permafrost.

In this paper, the major methods for construction and their effects as well as engineering problems after operation for the railway are introduced in details.

\section{The Major Methods for Construction}

Several active methods are developed and taken to protect permafrost along QTR, which include crushed-stone embankment, heat pipe embankment, bridge on land, and other assistant methods, such as, the ventilated-pipe embankment, the awning embankment, the heat preservation materials and heat pipe multiembankment etc. They have been applied in engineering design and construction .

(1) Crushed stone Roadbed: Much of the embankments are protected with "crushed stone", which are coarse, angular pieces of rock used to stabilize the surface. The crushed stone shield the roadbeds, embankments or both of them from solar heating and cool them by convection to maintain a higher thaw depth, which thus protects the permafrost (Fig.1).

(2) Heat Pipe Embankment: Heat pipes stabilize permafrost by removing heat from permafrost and dissipating it into the ambient cold air. They employ evaporative cooling to transfer thermal energy from one point to another by evaporation and condensation of a coolant. The ground temperature of the permafrost decreases when the vaporizing section in the permafrost absorbs warm energy, while the materials turn into gas from liquid (Fig.1).

(3) Dry Bridge (Bridge Instead of Roadbed): If the annual average ground temperature of the permafrost is very high $\left(0-0.5^{\circ} \mathrm{C}\right)$, it's not sufficient for protecting permafrost under the embankment. To minimize the thermal disturbance caused by construction, we adopted bridges instead of roadbeds to across over the permafrost land. The Qingshui river bridge is the longest one along QTR(Fig.1). 
(4) Ventilated-pipe Embankment: The ventilated-pipe roadbed has an open pipe installed beneath the roadbed through the embankment that cools the ground (Fig.).

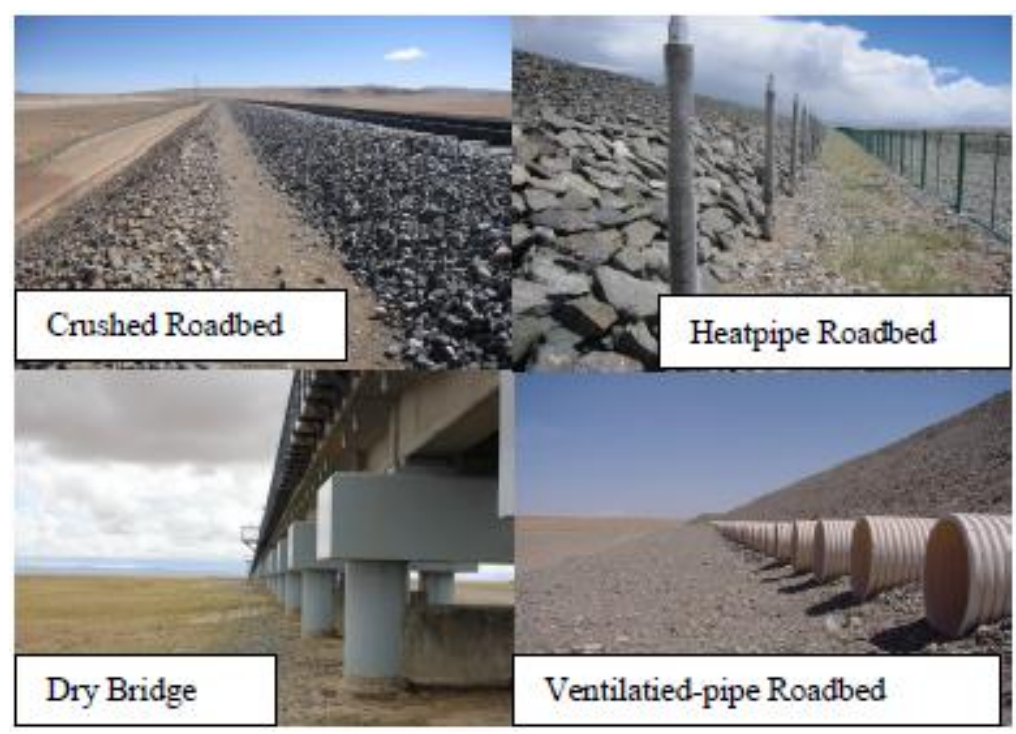

Fig. 1 Examples of engineering measures applied in QTR

\section{Long-Term Monitoring System}

\subsection{Monitoring system}

The deformation of the permafrost is a relatively long-term and slow process. The temperature profiles, the permafrost table and the variations of mean annual ground temperatures can be obtained from inspecting the soil temperatures, which directly reflect the thermal regimes of roadbed.

In order to investigate the deformation, the monitoring system has been constructed since 2001, which includes the deformation monitor (fig.2), 6 spots at each transect every $100 \mathrm{~m}$ along the $546.41 \mathrm{Km}$ of permafrost regions, and the temperature monitor (fig.2), a total of 100 monitoring section with 6 temperature monitoring holes at each transect. The degradations are measured every 15 days manually; however, the temperature data are collected automatically every 1 hour and transferred wirelessly from the field in situ to the lab in Golmud. 


\subsection{Deformation and Ground temperature of embankments.}

The cumulative embankment deformations at monitoring profiles located in warm unstable permafrost region, for example, is shown in Table 1 from October 2005 to December 2009 (Wei Ma, 2011).

In warm unstable permafrost region, all embankments experienced settlement but to varying degrees. For CRE, the settlements were less than 35 $\mathrm{mm}$, meaning that MASRs of these embankment were less than $10 \mathrm{~mm} / \mathrm{a}$, and the differential settlements between right and left embankment shoulders were small than $10 \mathrm{~mm}$. Whereas for TE, the settlements and differential settlements between right and left embankment shoulders were significant at some monitoring profiles, and the maximum magnitudes of them were $93 \mathrm{~mm}$ and 53 $\mathrm{mm}$, respectively.

Table 1 Cumulated embankment deformations at monitoring profiles located in warm unstable permafrost region

\begin{tabular}{llcccccc}
\hline $\begin{array}{l}\text { QTR } \\
\text { kilometer } \\
\text { post }\end{array}$ & $\begin{array}{l}\text { MAGT } \\
\left({ }^{\circ} \mathrm{C}\right)\end{array}$ & $\begin{array}{l}\text { Permafrost } \\
\text { conditions }\end{array}$ & ES & $\begin{array}{l}\text { EH } \\
(\mathrm{m})\end{array}$ & $\begin{array}{l}\text { EO } \\
\left({ }^{\circ} \mathrm{C}\right)\end{array}$ & \multicolumn{2}{l}{$\begin{array}{l}\text { Cumulative embankment } \\
\text { deformation(mm) }\end{array}$} \\
\cline { 5 - 7 } & & & & & & $\begin{array}{l}\text { Left } \\
\text { shoulder }\end{array}$ & $\begin{array}{l}\text { Right } \\
\text { shoulder }\end{array}$ \\
\hline K1014+895 & -0.75 & F,D & TE & 5.5 & 259.6 & -93 & -40 \\
K1033+082 & -0.9 & D & TE & 4 & 243.6 & -19 & -9 \\
K1166+550 & -0.65 & B,D & TE & 3.5 & 230.8 & -77 & -38 \\
K1254+020 & -0.74 & H,F,D & CRE & 3.4 & 174.5 & -19 & -16 \\
K1262+192 & -0.8 & F & CRE & 3.6 & 170.8 & -33 & -23 \\
K1392+250 & -0.9 & B,F & CRE & 4.4 & 270 & -31 & -24 \\
\hline
\end{tabular}

The comparison illustrated that ground temperature of embankment maintained stable, namely, the permafrost table beneath embankment was maintained at original level, but permafrost beneath the table to depth of $13 \mathrm{~m}$ was warmer than that under natural ground surface (Fig. 3).

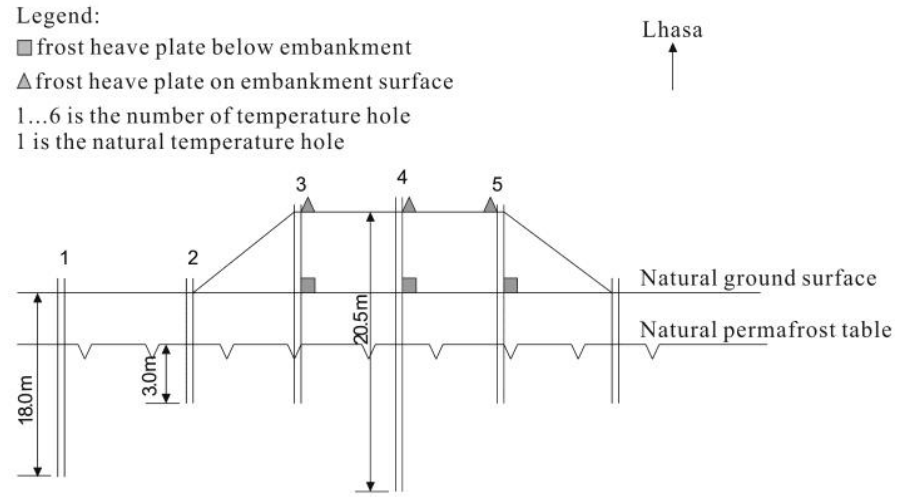

Fig. 2 A typical distribution of monitoring transect for temperatures and deformation (Ma Wei, 2005). 


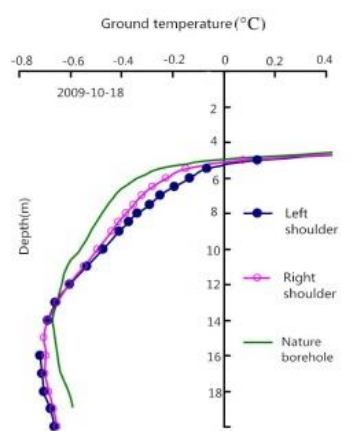

Fig. 3 Monitoring results at monitoring profile K1166+550.(Wei Ma, 2011)

\section{The Major Engineering Problems and Their Solutions}

The QTR has kept operating very well for nearly 10 years so far. Several active methods to protect permafrost, including slice roadbed, riprap roadbeds, and heat pipe roadbed. While kinds of problems have happened in early days of operation. The major three engineering problems are railway embankment crack and deformation.

\subsection{The major engineering problems.}

(1)Railway embankment cracks. Since operation, many cracks were found, the biggest crack in embankment was about $30 \mathrm{~cm}$ width and $35 \mathrm{~cm}$ length. On April, 2008, 21 cracks were found, 16 cracks located in embankment shoulder and berm, 4 cracks in cut slope and top of slope, and 1 crack in part-cut and part fill berm.

(2)Railway embankment deformation. The settlement after track laying is called settlement after construction, which is allowed, less than $20 \mathrm{~cm}$ totally, $10 \mathrm{~cm}$ in bridge transition section and $5 \mathrm{~cm}$ per year (TB10001-2005).

Some typical deformations in bridge transition section are shown in table 2 during April 2010 and April 2011, in which most of deformations are beyond $20 \mathrm{~mm}$ per year, that shows these embankment still are unstable.

Table 2 Typical deformations in bridge transition section (Zhiwen Xiong, 2011)

\begin{tabular}{cccc}
\hline No. & sections & deformation $/ \mathrm{mm}$ & locations \\
\hline 1 & K973+551 & 43 & Golmud side \\
2 & K1161+428 & 25 & Golmud side \\
3 & K1250+017 & 16 & Golmud side \\
4 & K1421+918 & 24 & Lhasa side \\
5 & K1424+400 & 35 & Golmud side \\
\hline
\end{tabular}




\subsection{Methods for cracks and deformation and theirs effects.}

\subsubsection{The major methods.}

(1) Slice stones of different thick were laid on both slopes of embankment, which can cool down embankment, decrease difference in ground surface temperature, help control cracks at their beginning, and degrade vibration on cracks.

(2) Earth berm must be built after filling low-lying parts on the toe of slope and another heat pipes should be designed inside sunny slope berm to keep from surface water and lower thaw depth.

(3) Filling or others project to keep from surface water should be designed when hot-thaw-ponds or irregular flows were near the toe of embankment.

(4) Reinforcement for cracks embankment. Filling in-situ were refilled and pounded layer by layer in cracks after digging until $0.3 \mathrm{~m}$ inside cracks horizontally and fresh surface vertically.

\subsubsection{Effects.}

\section{(1) Cracks.}

Table 3 shows conditions of cracks fixed in July 30, 2007, one year after cracks found in summer, 2006 according to above methods.

Table 3 Conditions one year after fixing cracks

\begin{tabular}{|c|c|c|c|c|}
\hline No. & Section & $\begin{array}{l}\text { Crack } \\
\text { length }\end{array}$ & Before fixing(summer,2006) & $\begin{array}{l}\text { After fixing(July } \\
30,2007)\end{array}$ \\
\hline 1 & $\mathrm{~K} 1001+585-615$ & $30 \mathrm{~m}$ & $\begin{array}{l}\text { Crack(The left shoulder and } \\
\text { toe of slope) }\end{array}$ & No crack \\
\hline 2 & K1004+300 & $30 \mathrm{~m}$ & Crack(The left shoulder) & No crack \\
\hline 3 & K1015+000 & $35 \mathrm{~m}$ & Crack(The left shoulder) & No crack \\
\hline 4 & $\mathrm{~K} 1112+605-625$ & $20 \mathrm{~m}$ & Crack(the right shoulder) & No crack \\
\hline 5 & $\mathrm{~K} 1113+340-360$ & $20 \mathrm{~m}$ & Crack(the right shoulder) & No crack \\
\hline 6 & $\mathrm{~K} 1116+280-300$ & $10 \mathrm{~m}$ & Crack(the right shoulder) & No crack \\
\hline 7 & $\mathrm{~K} 1128+500-540$ & $20 \mathrm{~m}$ & Crack(the right shoulder) & No crack \\
\hline 8 & $\begin{array}{l}\mathrm{K} 1132+685-720 \\
\mathrm{~K} 1132+800-840\end{array}$ & $\begin{array}{l}40 \mathrm{~m} \\
35 \mathrm{~m}\end{array}$ & Crack(the left shoulder) & No crack \\
\hline 9 & K1139+390-420 & $30 \mathrm{~m}$ & Crack(the left shoulder) & No crack \\
\hline 10 & K1146+400-430 & $30 \mathrm{~m}$ & Crack(the left shoulder) & No crack \\
\hline 11 & $\mathrm{~K} 1168+040-060$ & $20 \mathrm{~m}$ & Crack(the right shoulder) & No crack \\
\hline
\end{tabular}




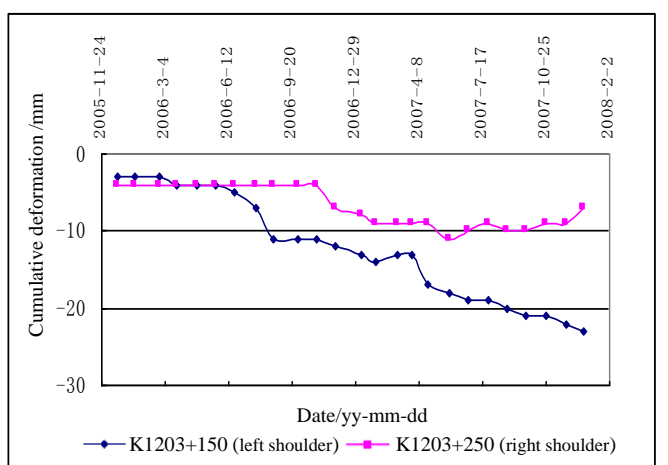

Fig. 4. Curve of accumulated deformation varying with time on section of K1203+150

(2) Railway embankment deformation. Embankment deformation of the typical section has become stable, which can make train operate well, according to data of about 2 years from 2005 to 2008(fig.4). According to data of table.4 about 2 years from operation (July 1, 2006) to June, 2008, among 40 sections monitored, 24 of which embankment accumulated deformation was less than $2 \mathrm{~cm}, 13$ of which from $2 \mathrm{~cm}$ to $5 \mathrm{~cm}, 2$ of which from $5 \mathrm{~cm}$ to $6 \mathrm{~cm}, 1$ of which more than $6 \mathrm{~cm}$. It proved all embankments of QTR was in good condition except for section of K1496+750.

Table 4 Cumulative deformation monitored of 40 sections from July, 2006 to June, 2008

\begin{tabular}{|c|c|c|c|c|}
\hline No. & $\begin{array}{l}\text { Cumulitive } \\
\text { deformation }\end{array}$ & $\begin{array}{l}\text { Sections } \\
\text { Number }\end{array}$ & Percent & Sections \\
\hline 1 & $<2 \mathrm{~cm}$ & 24 & $60 \%$ & $\begin{array}{l}\text { K0977+730 K1037+340 K1045+350 K1058+750 } \\
\text { K1076+706 K1082+575 K1091+613 K1093+710 } \\
\text { K1101+795 K1101+860 K1139+771 K1144+325 } \\
\text { K1152+225 K1190+650 K1201+860 K1215+560 } \\
\text { K1231+260 K1254+020 K1333+584 K1392+250 } \\
\text { K1404+750 K1461+397 K1464+133 K1497+845 }\end{array}$ \\
\hline 2 & $\begin{array}{l}2 \mathrm{~cm} \leq \\
<5 \mathrm{~cm}\end{array}$ & 13 & $32.5 \%$ & $\begin{array}{c}\text { K1034+090 K1038+670 K1118+240 K1161+625 } \\
\text { K1169+941 K1203+150 K1216+165 K1243+648 } \\
\text { K1267+120 K1286+197 K1312+270 K1323+060 } \\
\text { K1485+340 }\end{array}$ \\
\hline 3 & $\begin{array}{l}5 \mathrm{~cm} \leq \\
<6 \mathrm{~cm}\end{array}$ & 2 & $5 \%$ & K1347+012 K1480+150 \\
\hline 4 & $\geq 6 \mathrm{~cm}$ & 1 & $2.5 \%$ & $\mathrm{~K} 1496+750$ \\
\hline
\end{tabular}

\section{Conclusions}

(1) All the active methods of riprap roadbeds, heat pipe roadbed and bridges over land for construction have been proved to be efficiency and practical, and 
may be useful to the other railway construction projects in high elevation and permafrost areas.

(2) The QTR has kept operating very well for nearly 10 years so far. While kinds of problems have happened in early days of operation. The major engineering problems are railway embankment crack and deformation. Some methods for these problems, including laying slice stones on slopes of embankment, building earth berm, filling to keep from water, and reinforcing cracks have existed, have applied after operation, which have been proved to be successful and efficient.

\section{References}

1. Wei Ma, Guodong CHENG, Qingbai WU et al.. "Application on idea of dynamic design in Qinghai-Tibet railway construction," Cold Regions Science and Technology, Vol. 41, No. 3, 165-173(2005).

2. Wei Ma, Yanhu Mu, Qingbai Wu, Zhizhong Sun, Yongzhi Liu,. Characteristics and mechanisms of embankment deformation along the Qinghai-Tibet Railway in permafrost regions. Cold Regions Science and Technology, Vol.67, 178-186(2011).

3. Zhijian $\mathrm{Wu}$, We Ma i, Yu Sheng, et al. "Cooling effectiveness analysis of the vent-pipe, cast-detritus and heat preservation material on protecting embankment in permafrost regions," Rock and Soil Mechanics, Vol. 26, No. 8, 1288-1293(2005) (In Chinese).

4. Zhiwen Xiong, , Study on Deformation Mechanism and Treatment Measures of pier and abutment in Permafrost Area along Qinghai-Tibet Railway, Ph.D. thesis(2011) (In Chinese).

5. General Administration of Quality and Technical Supervision. "Code for seismic safety evaluation of engineering sites (GB 17741-1999).” Standards Press of China, Beijing(1999) (In Chinese).

6. General Administration of Quality and Technical Supervision. "Seismic shock parameter zonation of China (GB 18306-2001)," Standards Press of China, Beijing(2001) (In Chinese).

7. IPCC. "Climate change 2001: the scientific basis, summary for policymakers and technical summary of working group I report,” Eds. By Houghton J T, Ding Yihui, D. Griggs et al., Cambridge University Press, 98(2001).

8. Fu-jun Niu, Qi-hao $\mathrm{Yu}$ and Yuan-ming Lai. "Analysis of ground temperature change and thermal process in the testing duct-ventilated embankment of the Qinghai-Tibet Railway," Journal of Glaciology and Geocryology, Vol. 48, No. 6, 614-260(2003). 